\title{
Engineered bamboo for structural applications
}

\author{
Bhavna Sharma *, Ana Gatóo, Maximilian Bock, Michael Ramage \\ Department of Architecture, University of Cambridge, Cambridge, UK
}

\section{H I G H L I G H T S}

- Relevance of engineered bamboo products to construction and industry.

- Mechanical characterisation of bamboo scrimber and laminated bamboo is presented.

- Bamboo scrimber is shown to have similar strength to laminated bamboo.

- Engineered bamboo products have properties that are equal to or surpass that of timber.

\section{A R T I C L E I N F O}

\section{Article history:}

Received 24 September 2014

Received in revised form 27 January 2015

Accepted 29 January 2015

Available online 23 February 2015

\section{Keywords:}

Bamboo scrimber

Engineered composites

Laminated bamboo

Construction

\begin{abstract}
A B S T R A C T
Bamboo is a rapidly renewable material that has many applications in construction. Engineered bamboo products result from processing the raw bamboo culm into a laminated composite, similar to gluelaminated timber products. These products allow the material to be used in standardised sections and have less inherent variability than the natural material. The present work investigates the mechanical properties of two types of commercially available products - bamboo scrimber and laminated bamboo sheets - and compares these to timber and engineered timber products. It is shown that engineered bamboo products have properties that are comparable to or surpass that of timber and timber-based products. Potential limitations to use in structural design are also discussed. The study contributes to a growing body of research on engineered bamboo and presents areas in which further investigation is needed. (c) 2015 The Authors. Published by Elsevier Ltd. This is an open access article under the CC BY license (http://
\end{abstract} creativecommons.org/licenses/by/4.0/).

\section{Introduction}

Bamboo has many advantages as a construction material: it is a rapidly renewable sustainable resource and has mechanical properties similar to timber. Worldwide, there is a growing interest in the development of bamboo products as a sustainable, costeffective and ecologically responsible alternative construction material [1]. Partially due to the faster growth rate, and therefore harvest cycle, bamboo forests have up to four times the carbon density per hectare of spruce forests over the long term [2]. Bamboo is found in rapidly developing areas of the world where often timber resources are limited [2]. While the potential of bamboo is promising, more widespread development and use of bamboo is hampered by the lack of engineering data for mechanical properties and appropriate building codes [3,4].

Bamboo is an anisotropic material, having mechanical properties that vary in the longitudinal, radial and transverse directions. The raw material is a giant grass consisting of a hollow culm having longitudinal fibres aligned within a lignin matrix, divided

\footnotetext{
* Corresponding author. Tel.: +44 (0)1223 760124.

E-mail address: bs521@cam.ac.uk (B. Sharma).
}

by nodes (solid diaphragms) along the culm length (Fig. 1). The thickness of the culm wall tapers from the base of the culm to the top. As a functionally graded material, the bamboo fibres also vary within the culm wall decreasing in density from the exterior to the interior (Fig. 1).

While there are more than 1200 species worldwide, full culm bamboo construction is limited by the variation in geometric and mechanical properties. The difficulty in making connections and joints suitable for round (and variable) sections is also prohibitive for mainstream construction; however increasing research demonstrates a growing industry and demand for sustainable building products. Studies vary from the use of full culm bamboo in construction and scaffolding (e.g., [5-10] to engineered bamboo composites (e.g., [11-21]. Engineered bamboo composites are of particular interest due to the standardisation of shape and the relatively low variability in material properties [22].

Two examples of engineered bamboo are bamboo scrimber and laminated bamboo [22]. Bamboo scrimber, also referred to as strand woven or parallel strand bamboo, consists of crushed fibre bundles saturated in resin and compressed into a dense block (Fig. 2). The process is materially efficient, utilising approximately 
$80 \%$ of raw inputs [23], and produces a product with a Janka hardness that is acceptable for external applications such as deck flooring. The process maintains the longitudinal direction of the bamboo fibres and utilises the resin matrix to connect the fibre bundles. In contrast, laminated bamboo maintains both the longitudinal fibres as well as a portion of the original culm matrix. The bamboo culm is split, planed, processed (bleached or caramelised), laminated and pressed to form the board product (Fig. 3). The orientation of the strip within the board, and therefore the direction of the radial fibre density, is randomly placed within in the board (Fig. 3). The final products use only approximately $30 \%$ of raw material input due to large losses of material when the strips are planed to form the rectangular section [23]. The sheet product is primarily used indoors for surface applications or furniture. While both materials are currently used for surface applications, both maintain the inherent strength of bamboo by maintaining the longitudinal fibre orientation and the engineered product creates a uniform section for connections and joints in structural applications.

The present work investigates the mechanical properties of bamboo scrimber and laminated bamboo to assess the potential for structural applications. A comparison with timber and engineered timber products is also presented.

\section{Materials and methods}

Two commercially produced products from China were used in the study. The bamboo scrimber product is comprised of Phyllostachys pubescens (Moso) with a phenol formaldehyde resin. The final product is a $140 \times 140 \mathrm{~mm}$ section available in varying lengths. As shown in Fig. 2 and discussed in the previous section, the process of manufacturing bamboo scrimber uses the bamboo culm with minimal processing. The resulting commercial product is tested as a final product with no additional modifications. The average density of the bamboo scrimber is $1160 \mathrm{~kg} /$ $\mathrm{m}^{3}$ with a moisture content of $7 \%$. In comparison, Moso as a raw material has a relative density of approximately $0.5-1.0$.

Laminated bamboo sheets are also manufactured from Moso bamboo strips using a soy-based resin as shown in Fig. 3 and discussed in the previous section. The structural specimens are built up from a commercial sheet $(2440 \times 1220 \times 19 \mathrm{~mm})$. The sheet was cut and the section laminated into the desired dimensions using polyurethane adhesive (Purbond HB S309). The adhesive was applied manually with a glue proportion of approximately $180 \mathrm{~g} / \mathrm{m}^{2}$ (final product) and the lamina pressed using manual clamps to apply the required pressure of $0.6 \mathrm{MPa}$ for 4 hours (Fig. 4). Two orientations were tested: radial horizontal and radial vertical, which refer to the orientation of the original strip within the beam,

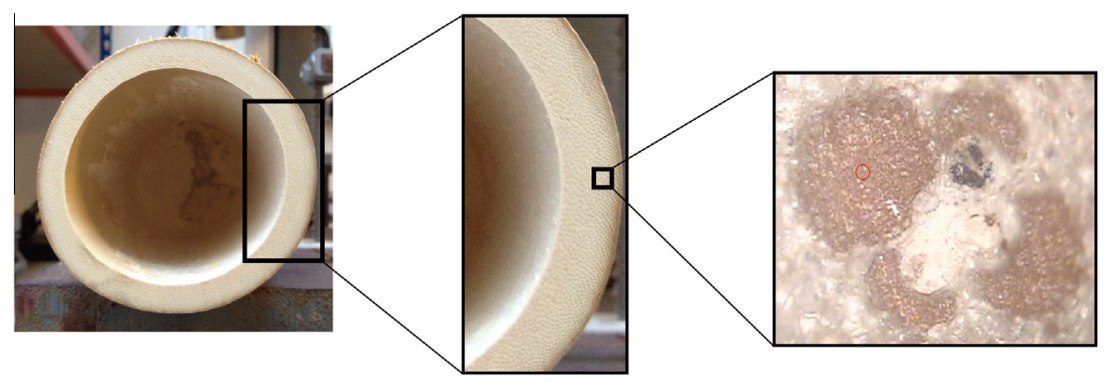

Fig. 1. Details of a bamboo culm.

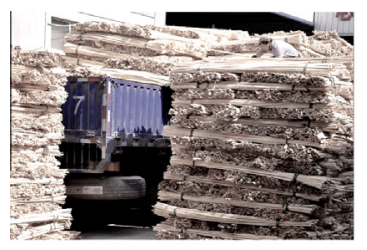

Bamboo strips

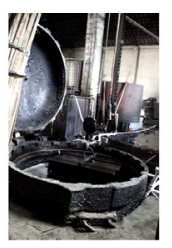

Resin

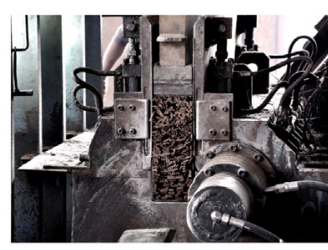

Compression

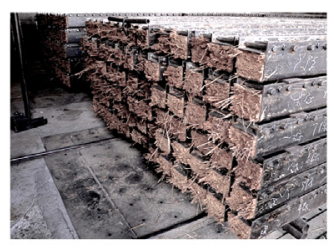

Heat Cured

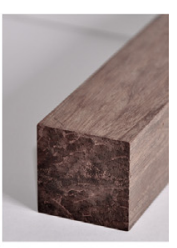

Bamboo Scrimber

Fig. 2. Bamboo scrimber general manufacturing process in China.

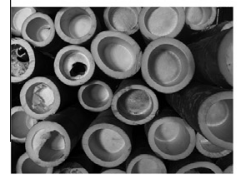

Culms

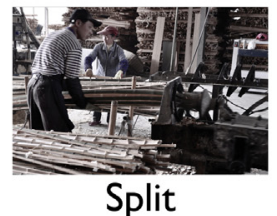

Split

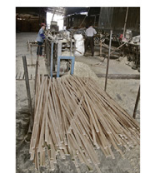

Planed

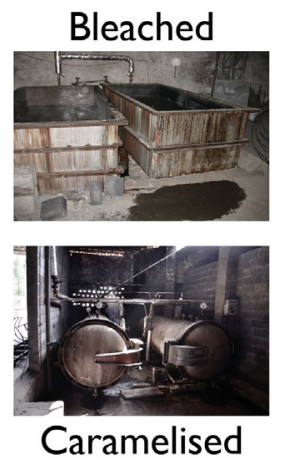

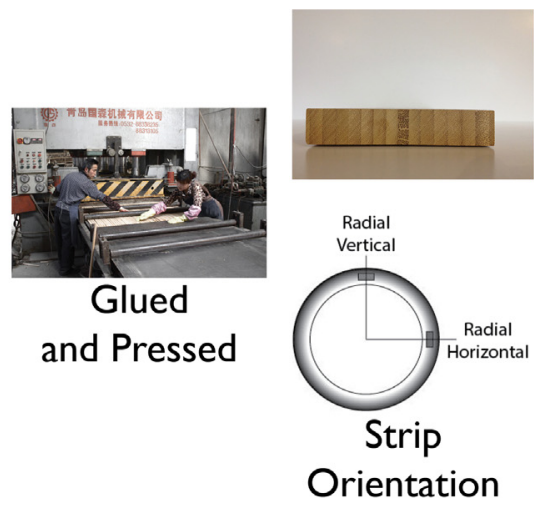

Glued and Pressed

Fig. 3. Laminated bamboo general manufacturing process in China. 
as shown in Fig. 3. The industry terminologies for the equivalent orientations are edgewise and flatwise respectively, which refer to the orientation of the strips within a board, however this terminology is not well-defined for beam sections. Therefore the two orientations are herein described as radial horizontal and radial vertical and are shown in Fig. 4. The laminated bamboo has an average density of $686 \mathrm{~kg} / \mathrm{m}^{3}$ with a moisture content of $6 \%$. All specimens are conditioned in a constant temperature of $23{ }^{\circ} \mathrm{C}$ and a relative humidity of $55 \%$ for 2 weeks before testing.

\subsection{Standard test methods used}

To obtain the material and mechanical properties, tension, compression, shear and flexural tests were conducted based on BS 373 Methods of testing small clear specimens of timber [24], ASTM D143 Standard Test Methods for Small Clear Specimens of Timber [25] and BS EN 408 Timber structures - Structural timber and glue-laminated timber [26]. BS 373:1957 cross references ASTM D143-09 and both are based on small clear specimens, whereas BS EN 408:2010 focuses on dimensional lumber samples. The standards, test methods, and test parameters used are summarised in Table 1.

Both materials were tested using the same method with the exception of the bending test. BS EN 408:2010 for four-point bending defines the specimen length and loading rate as a function of the cross-sectional size. Due to the size limitations of the bamboo scrimber, it was necessary to test different dimensions and loading rate as given in Table 1. For all other mechanical tests, the small clear specimens were obtained from the beams at random and cut to the specified size [24,25]. For the tension parallel to grain, the specimens have two profiles specified in ASTM D143 [25]. They were initially cut with a water-jet and then routed to complete the second profile. Tension, compression and shear tests were conducted in a universal testing machine. All displacements are measured from the crosshead travel of test frame and the compliance of the frame was taken into account.

\section{Experimental results}

A summary of the test results is presented in Table 2 with additional observations for each mechanical property presented in the sections below. All of the mechanical properties were calculated in the linear elastic region at the limit of proportionality as required by the standards. Table 2 lists the average $(\bar{x})$ and the coefficient of variation (COV); ten specimens were tested in every case (i.e., $n=10)$.

\subsection{Tension}

Fig. 5 shows a comparison of representative failures for both parallel to grain and perpendicular to grain tests. In tension parallel to grain $\left(f_{t \|}\right)$, both the bamboo scrimber and the laminated bamboo exhibited linear behaviour prior to failure. The tension perpendicular to grain $\left(f_{t \perp}\right)$ results emphasises the low strength of the bamboo scrimber and the laminated bamboo perpendicular to the fibre direction. The majority of the failures occurred at various locations within the anvil (Fig. 5) and through the bamboo rather than within the adhesive for both materials. The parallel tensile strength was more than forty times the perpendicular strength.

\subsection{Compression}

The compression parallel to grain $\left(f_{c \|}\right)$ results for both materials are shown in Fig. $6 a$ and in Table 2. The failure mode of the bamboo scrimber was overall section buckling of the specimen (Fig. 6). A similar failure was noted by Huang et al. [14] in larger $(105 \times 105 \times 315 \mathrm{~mm})$ bamboo scrimber specimens. All of the laminated bamboo specimens failed in overall section buckling with no shear failures observed. Li et al. [33] also noted the buckling failure in larger samples $(100 \times 100 \times 300 \mathrm{~mm})$ in compression parallel to grain specimens that were manufactured

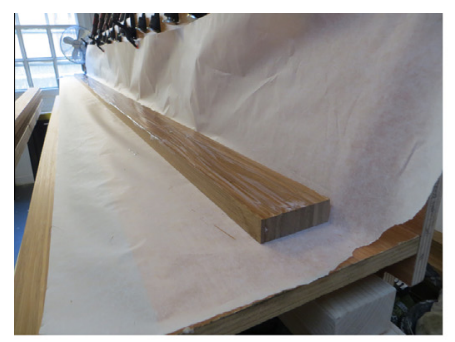

(a)

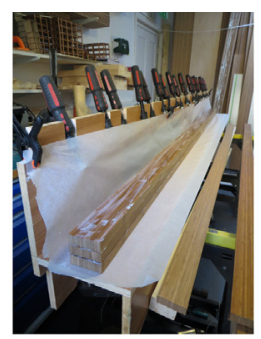

(b)

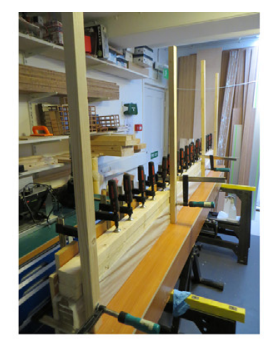

(c)

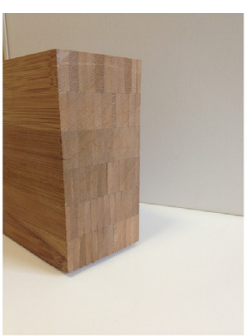

(d)

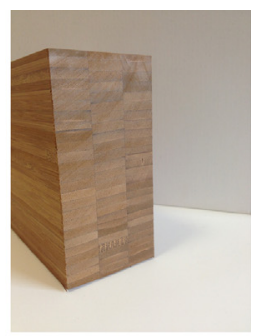

(e)

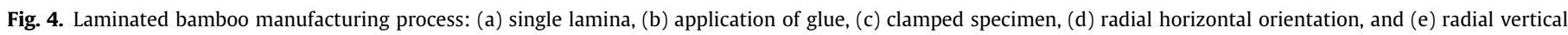
orientation.

Table 1

Experimental test methods for bamboo scrimber and laminated bamboo.

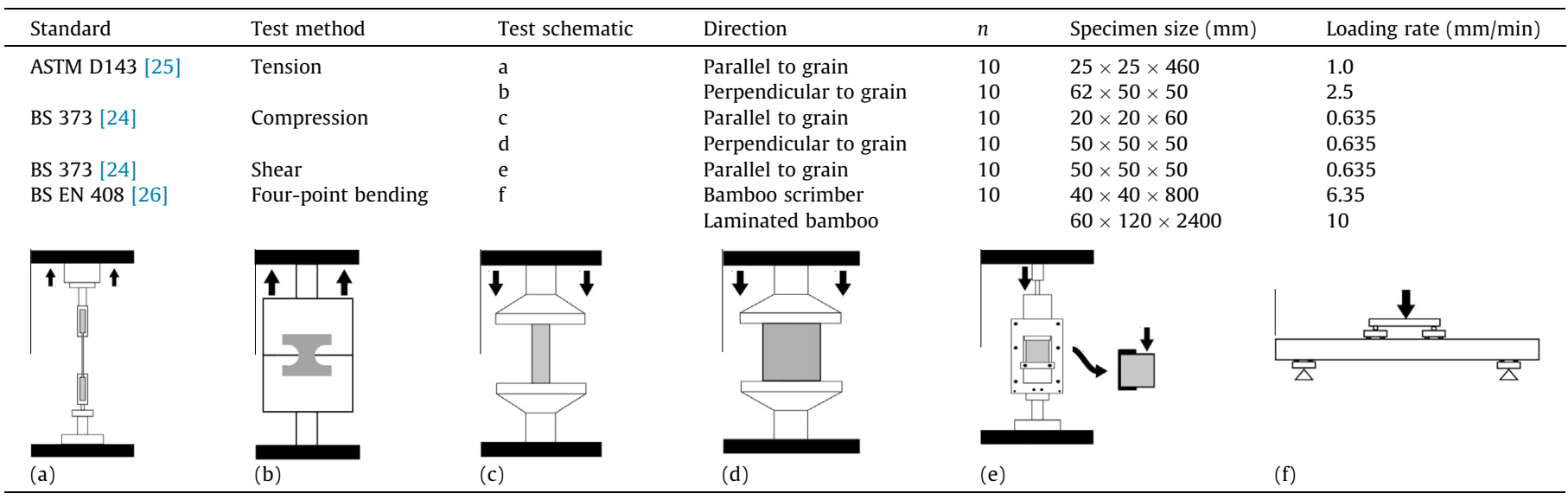


Table 2

Material properties for structural bamboo and comparable natural bamboo and timber products.

\begin{tabular}{|c|c|c|c|c|c|c|c|c|c|c|}
\hline & & \multirow{2}{*}{$\begin{array}{c}\text { Density } \\
\rho \\
\mathrm{kg} / \mathrm{m}^{3}\end{array}$} & \multicolumn{2}{|c|}{ Compression } & \multicolumn{2}{|c|}{ Tension } & \multirow{2}{*}{$\begin{array}{c}\text { Shear } \\
\tau_{\|} \\
\mathrm{MPa}\end{array}$} & \multicolumn{2}{|c|}{ Flexural } & \multirow{2}{*}{$\begin{array}{c}\frac{E_{b}}{\rho} \\
10^{6}\left(\mathrm{~m}^{2} \mathrm{~s}^{-2}\right.\end{array}$} \\
\hline & & & $\begin{array}{c}f_{c \|} \\
\mathrm{MPa}\end{array}$ & $\begin{array}{l}f_{c \perp} \\
\mathrm{MPa}\end{array}$ & $\begin{array}{c}f_{t \|} \\
\mathrm{MPa}\end{array}$ & $\begin{array}{l}f_{t \perp} \\
\mathrm{MPa}\end{array}$ & & $\begin{array}{c}f_{b} \\
\mathrm{MPa}\end{array}$ & $\begin{array}{c}E_{b} \\
\mathrm{GPa}\end{array}$ & \\
\hline \multirow[t]{2}{*}{ Laminated bamboo ${ }^{\mathrm{a}}$} & $\bar{x}$ & 686 & 77 & 22 & 90 & 2 & 16 & 77-83 & $11-13$ & $16-19$ \\
\hline & $\mathrm{COV}$ & 0.05 & 0.05 & 0.07 & 0.26 & 0.13 & 0.05 & $0.06-0.08$ & $0.05-0.06$ & \\
\hline \multirow[t]{2}{*}{ Bamboo scrimber $^{\mathrm{a}}$} & $\bar{x}$ & 1163 & 86 & 37 & 120 & 3 & 15 & 119 & 13 & 11 \\
\hline & $\mathrm{COV}$ & 0.02 & 0.02 & 0.05 & 0.14 & 0.13 & 0.11 & 0.08 & 0.04 & \\
\hline $\begin{array}{l}\text { Raw Bamboo Phyllostachys } \\
\text { pubescens }{ }^{\text {b,c }}\end{array}$ & $\bar{x}$ & 666 & 53 & - & 153 & - & 16 & 135 & 9 & 14 \\
\hline Sitka spruce ${ }^{\mathrm{d}, \mathrm{e}}$ & $\bar{x}$ & 383 & 36 & - & 59 & - & 9 & 67 & 8 & 21 \\
\hline Douglas-fir LVL ${ }^{\mathrm{f}, \mathrm{g}}$ & $\bar{x}$ & 520 & 57 & - & 49 & - & 11 & 68 & 13 & 25 \\
\hline
\end{tabular}

a Present study.

b Ghavami and Marinho [27].

c de Vos [28].

d Lavers [29].

e Kretschmann [30].

${ }^{f}$ Kretschmann et al. [31].

g Clouston et al. [32].

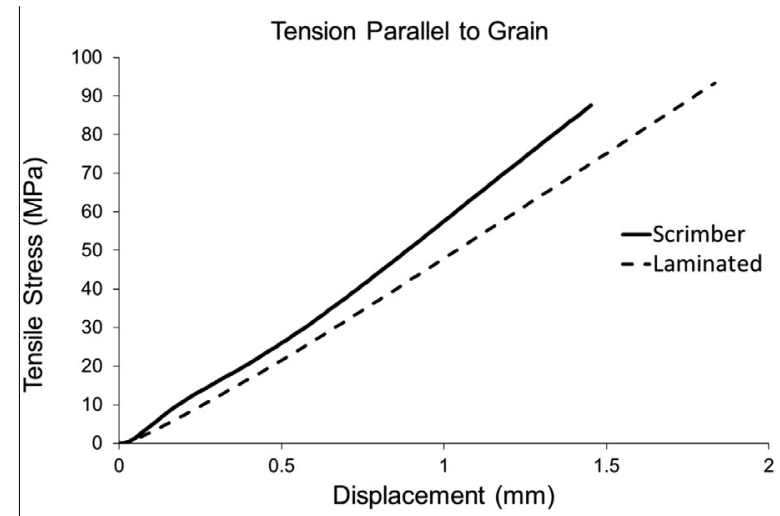

(a)

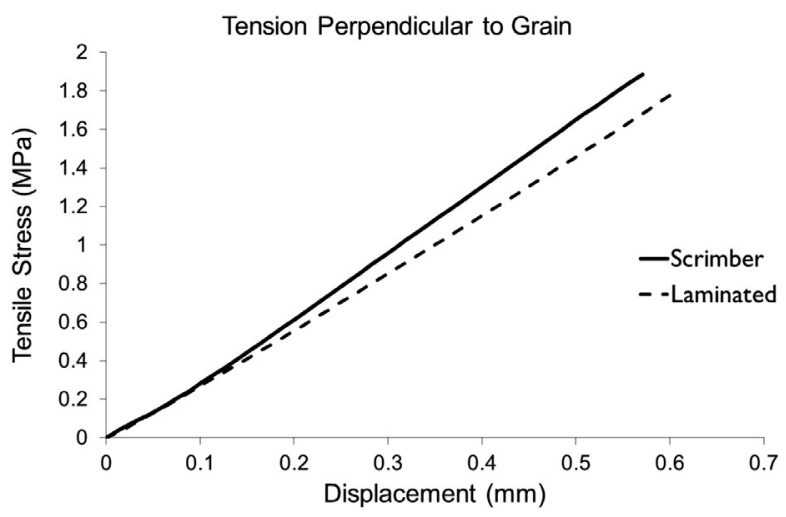

(d)

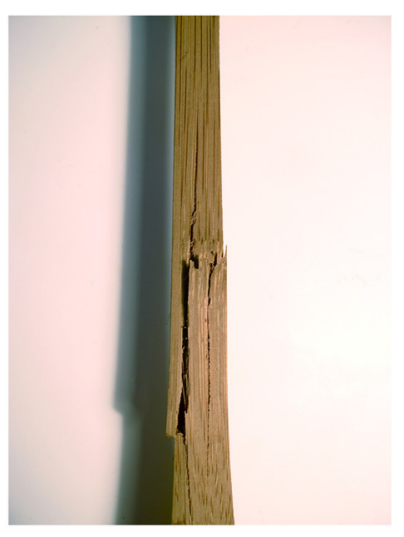

(b)

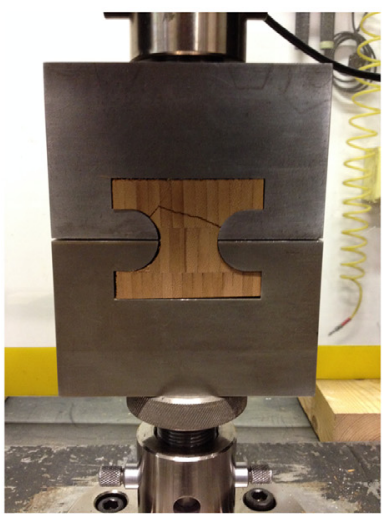

(e)

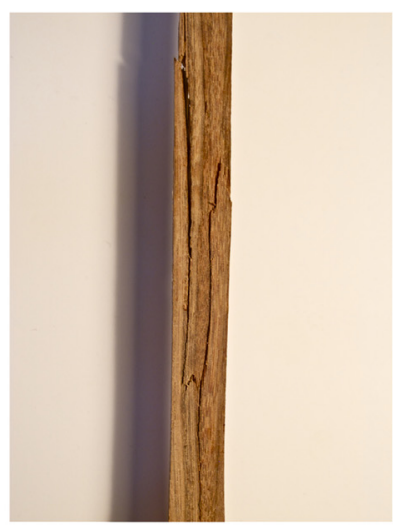

(c)

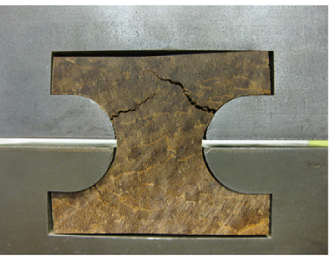

(f)

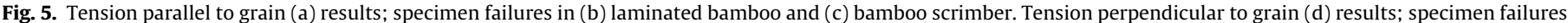
in (e) laminated bamboo and (f) bamboo scrimber.

from the upper portion of the bamboo with laminates of approximately $4 \mathrm{~mm}$ in thickness, similar to the specimens tested here ( 4-6 mm). The representative curves show that both materials exhibit bilinear behaviour, which has also been observed in other studies [14,33]. Because specimen buckling dominates behaviour, the compressive strength is determined at the proportional limit in all cases (the knee in the bilinear curve). Thus this value must be interpreted as the strength for the sample dimension used rather than the compressive capacity of the material.
The materials had a reduced strength in compression perpendicular to grain $\left(f_{t \perp}\right)$, in comparison to the parallel to grain direction (see Table 2). Both displayed bilinear behaviour and the bamboo scrimber achieved twice the load at similar displacements before failure (Fig. 6b). The failure mode for both materials was fracture of the matrix and bamboo fibres. For bamboo scrimber, the material demonstrated a slight influence of the direction of the glue line (i.e. the direction of the initial manufacturing compression), showing a $5 \%$ increase in stress 


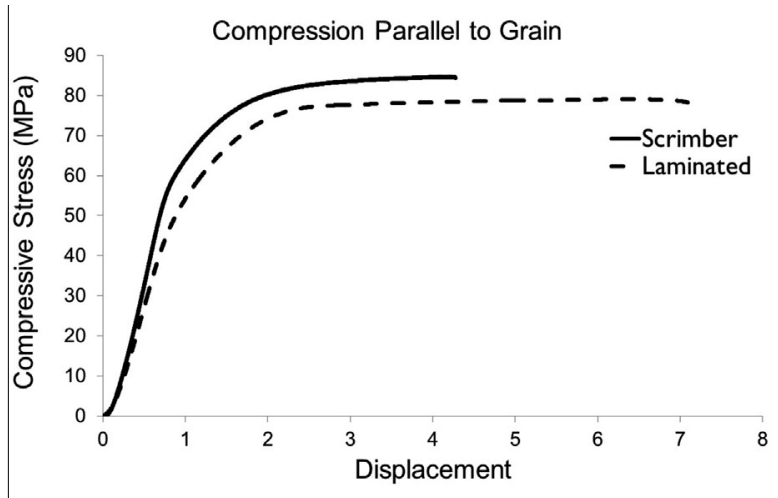

(a)

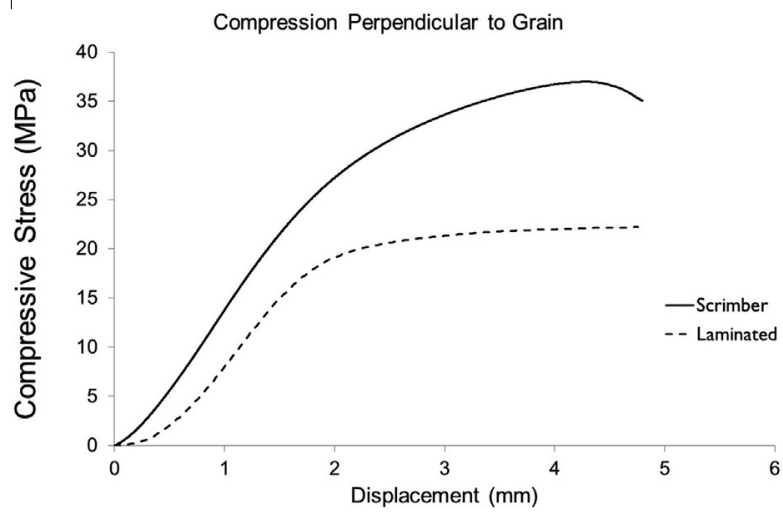

(d)

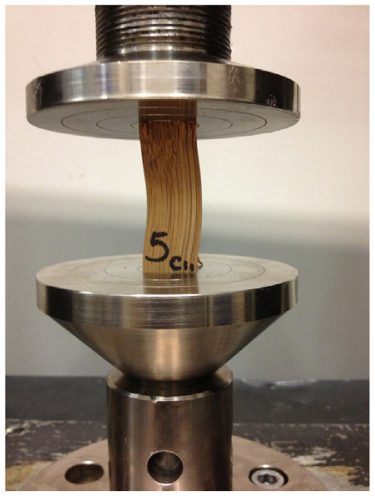

(b)

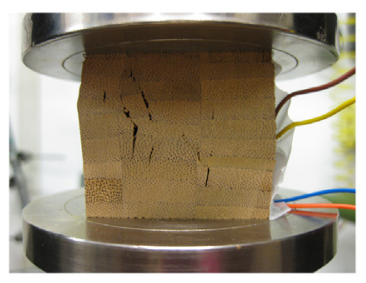

(e)

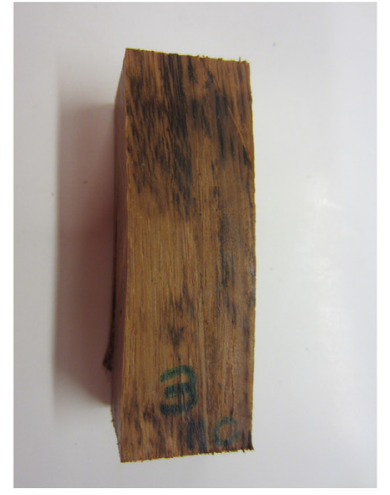

(c)

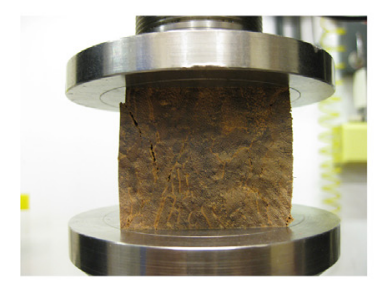

(f)

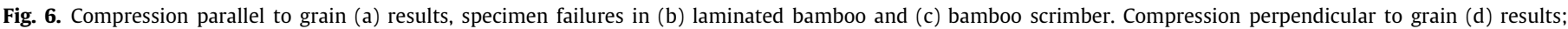
specimen failures in (e) laminated bamboo and (f) bamboo scrimber.

parallel to the glue line. In comparison, the laminated bamboo showed no influence of the direction of the glue line (Table 2).

\subsection{Shear}

In shear parallel to grain $\left(\tau_{\|}\right)$, the behaviour of the two materials is quite similar, however the laminated bamboo is able to withstand increased load and displacement before failure. The laminated bamboo is noted to have a higher compressibility before the shear failure occurred within the fibres. The failure surface of the bamboo scrimber was much rougher (see Fig. 7). The average shear strength, however, was comparable with the laminated bamboo, slightly higher (16 MPa) than the bamboo scrimber (15 MPa).

\subsection{Bending}

Bending results for the bamboo scrimber are shown in Fig. 8a. The results indicated that a large displacement was achieved in the specimens before failure. Failure occurred at the tension faces of the specimens at mid-span. Similarly, the laminated bamboo failures occurred near mid-span, although these were characterised as longitudinal shear failures (i.e. VQ/I failures) within the

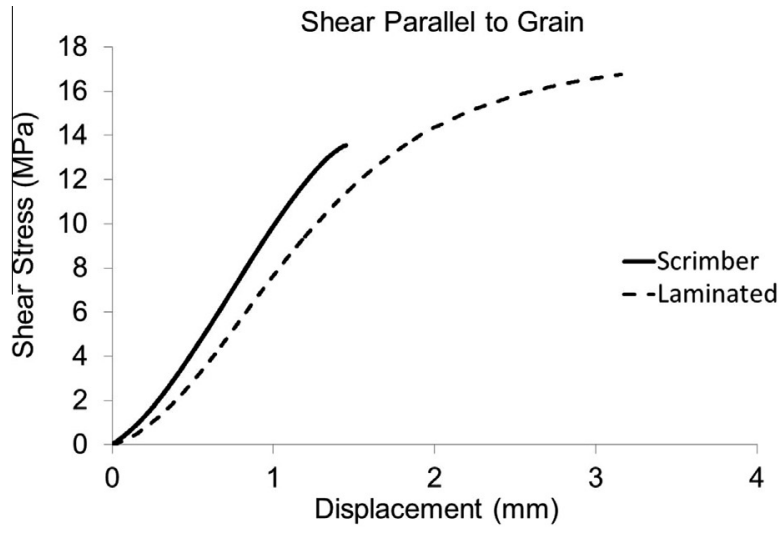

(a)

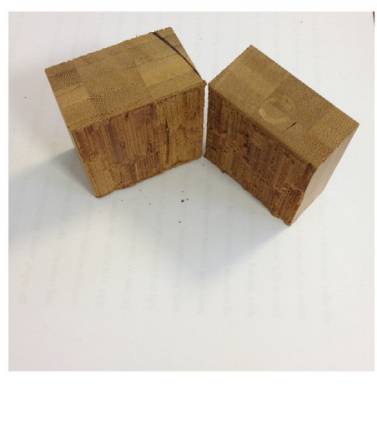

(b)

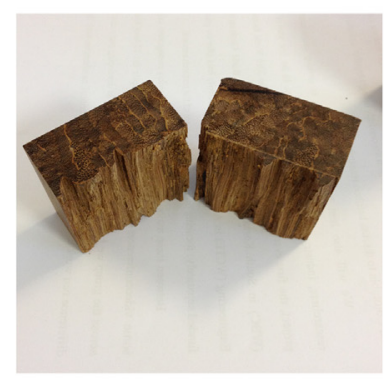

(c)

Fig. 7. Shear Parallel to Grain (a) results; specimen failures in (b) laminated bamboo and (c) bamboo scrimber. 


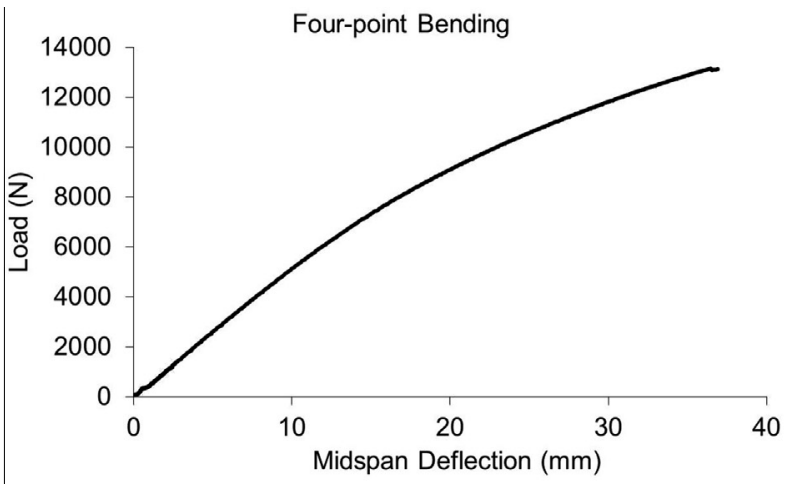

(a)

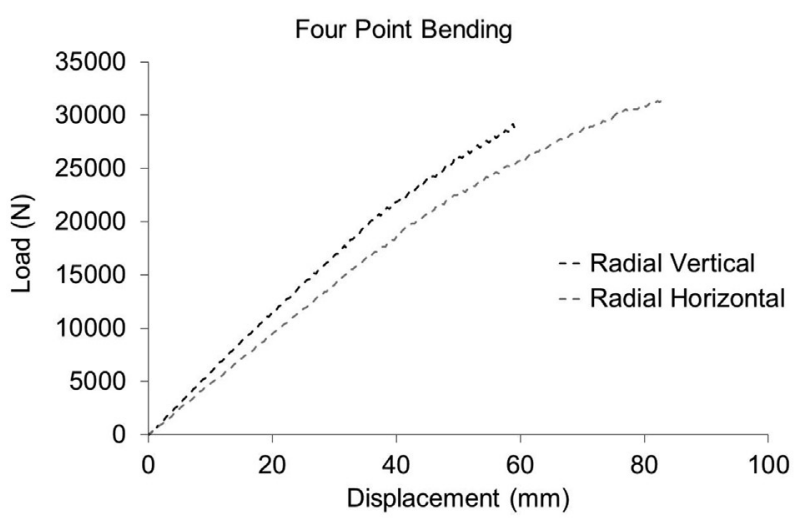

(d)

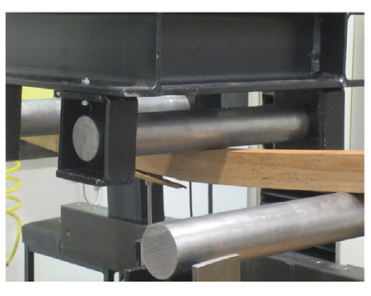

(b)

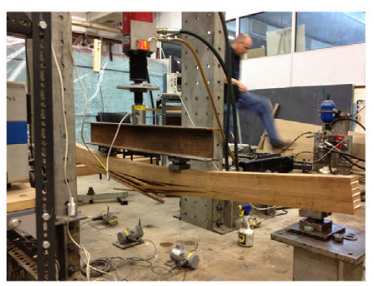

(e)

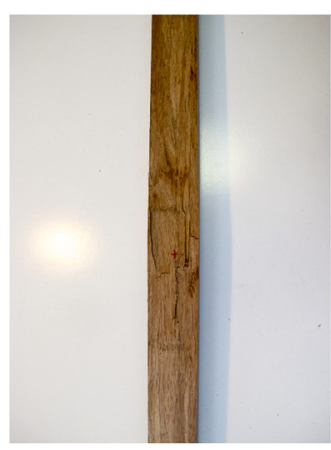

(c)

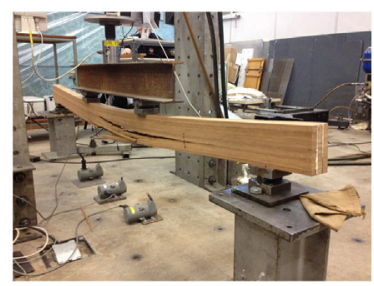

Fig. 8. Four point bending (a) results and (b) specimen failure for bamboo scrimber. Laminated bamboo (c) results and specimen failures for (d) radial horizontal and (e) radial vertical orientations.

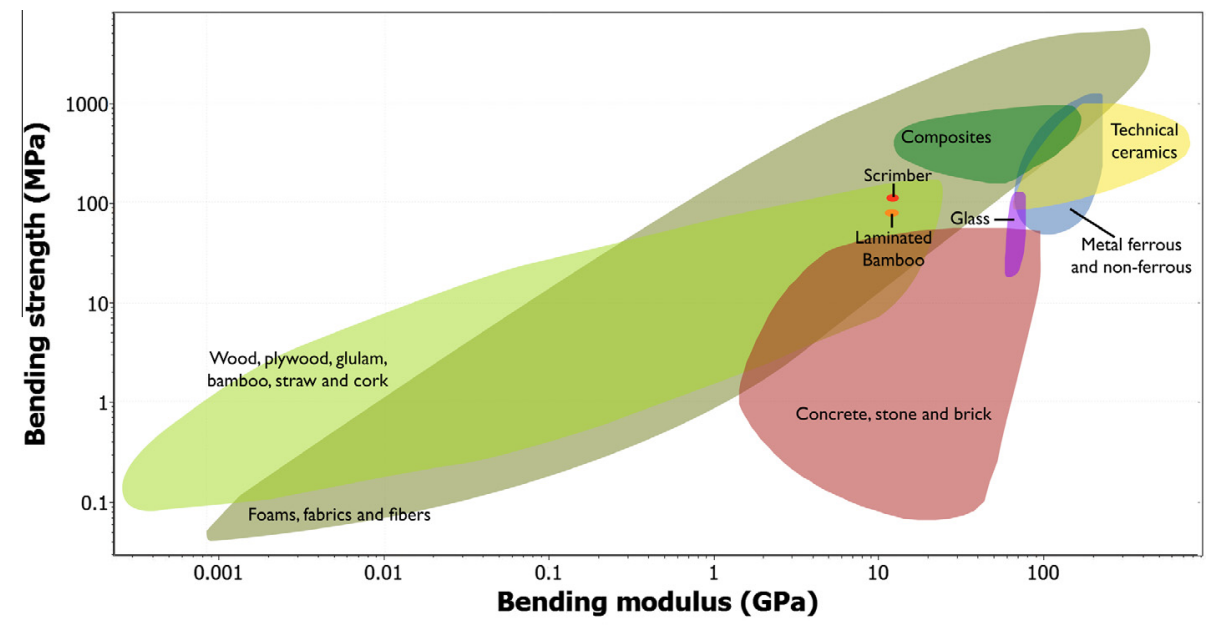

Fig. 9. Bending modulus vs. bending strength for various construction materials [35].

depth of the beam for both the edgewise and flatwise oriented specimens (Fig. 8b). All of the laminated bamboo specimens demonstrated brittle failure. Although micro-cracks within the material were audible and are also observed in small drops along the loaddisplacement curve (Fig. 8b), no cracks were visible before failure. Comparison of the two orientations indicates that while achieving similar maximum loads, the flatwise orientation had an increased modulus of elasticity with a gain of approximately $18 \%$ over the edgewise orientation (Table 2).

\section{Discussion}

Both engineered bamboo materials, scrimber and laminated bamboo, exhibit the anisotropic behaviour typical of natural bamboo, and similar to that of fibre reinforced composites [34]. The mechanical behaviour of bamboo scrimber and laminated bamboo are very similar in tension, compression and shear parallel to grain. The laminated bamboo, however, has increased post-peak load deformation capacity, which is attributed to the compressibility 
of the matrix. Perpendicular to the fibre direction, the materials are also very similar, with the exception of compression where the bamboo scrimber has approximately twice the compressive strength of the laminated bamboo (Table 2). Overall, bamboo scrimber has slightly higher strengths in all properties with the exception of shear parallel to grain. The increased capacity is attributed to the densified fibres within the phenol formaldehyde resin. In flexure, engineered bamboo has the capacity to resist large amounts of compression at the top of the beam, with failure occurring near the tension face at mid-span.

\subsection{Comparison to timber}

The results of the study indicate that engineered bamboo has comparable mechanical properties to other structural materials like timber and raw bamboo. Table 2 provides a comparison of the presented results to mechanical properties from different experimental studies on timber, laminated veneer lumber (LVL) and raw bamboo. Due to the longitudinal strength of the bamboo fibres, both bamboo scrimber and laminated bamboo have increased strength in properties parallel to grain, with the exception of tension parallel to grain. Similar to timber, the strength perpendicular to grain is significantly lower than the strength parallel to grain.

An advantage of laminated bamboo is its flexural strength to density ratio. The specific bending modulus $\left(E_{b} / \rho\right)$ is shown in Table 2. Laminated bamboo has a similar specific modulus (16$\left.19\left(10^{6} \mathrm{~m}^{2} \mathrm{~s}^{-2}\right)\right)$ to Sitka spruce $\left(21\left(10^{6} \mathrm{~m}^{2} \mathrm{~s}^{-2}\right)\right)$ and Douglas-fir $\operatorname{LVL}\left(25\left(10^{6} \mathrm{~m}^{2} \mathrm{~s}^{-2}\right)\right)$ and surpasses that of bamboo scrimber (11 $\left.\left(10^{6} \mathrm{~m}^{2} \mathrm{~s}^{-2}\right)\right)$. Further comparison of the bending properties for various construction materials to engineered bamboo composites is shown in Fig. 9. The graph illustrates that the flexural strength of engineered bamboo is on the higher end of the natural composite envelope and lower than fibre reinforced polymers composites. The failure mode of engineered bamboo must also be considered in comparison to other materials. Additional research is needed to understand the failure mode of the material and in particular the shear strength proportional to longitudinal capacity.

\subsection{Timber test methods}

Timber standards are increasingly used in bamboo research and industry to characterise the material. While the observed failure modes and strengths appear to be similar to timber, further research is needed to understand the influences and applicability of the timber-based test methods for full-culm or engineered bamboo. For example, the BS EN 384: Structural timber - Determination of characteristic values of mechanical properties and density [36], applies factors to determine characteristic values for structural timber. The standard mechanical properties are defined for $12 \%$ moisture content with factors applied to the different properties to adjust for differences. A Chinese standard, Testing methods for physical and mechanical properties of bamboo used in building, also adjusts for $12 \%$ moisture content in full culm bamboo [37]. Engineered bamboo is at equilibrium at about $6 \%$ moisture content, well below $12 \%$ typical in timber and full-culm bamboo, and the impact on the mechanical properties has yet to be fully established. With increased moisture content above the material saturation point (MSP), timber demonstrates dimensional instability and decreases in strength. For example, the compressive strength increases rapidly as the moisture content decreases from the MSP [38]. Similarly, Wang et al. [39] and Xu et al. [40] explored the effect of moisture content and density on the compressive strength parallel to grain of bamboo elements and found that the compressive strength decreases rapidly until the material reached the saturation point. As natural materials, the impact of the uncer- tainty in the material is reflected in design factors, which can reduce the allowable strength properties significantly and affect the comparison to conventional materials.

Another example is the buckling failure observed in compression parallel to grain tests in this and other studies [12,33,14]. The buckled shape is not an acceptable failure mode in timber specimens [24] and as discussed previously, does not represent the compressive strength of the material. The failure mode of the fibres within the matrix need to be further investigated to determine the mechanism at which failure in compression occurs and the relationship to the flexural buckling strength of the material.

To fully standardise engineered bamboo products, the test methods used to characterise the material must be evaluated to determine any influences or effects on the results. For example, bamboo scrimber and laminated bamboo in bending have similar properties to timber and glulam, however additional testing is needed to determine whether there are any bamboo-based factors that need to be applied to calculate appropriate characteristic values.

\section{Summary}

The present work characterises the mechanical properties of two types of commercial products: bamboo scrimber and laminated bamboo. The study utilised timber standards for characterisation, which allows for comparison to timber and engineered timber products. The results of the study indicate that both products have properties that compare with or surpass that of timber.

Bamboo scrimber and laminated bamboo are heavily processed before testing. Future work includes investigating the influence of processing on the material properties. In particular, the impact of heat treatment performed on the material to achieve a caramel colour. A comparison study on natural coloured bamboo will provide better understanding of the effects of heat treatment on the strength of the material. The beam section can be optimised to take advantage of the high flexural strength to density ratio. Research on the influence of the orientation of the original board on the stiffness will also allow for further optimisation. Further investigation of the influence of moisture and the density on the mechanical properties is needed to provide a foundation from which to develop design characterisation factors for engineered bamboo. Additional testing of full-scale specimens would also elucidate any effects in comparison to small clear specimens, as well as allow further comparison to timber and provide an additional step forward towards construction.

\section{Acknowledgements}

The presented work is supported by EPRSC Grant EP/K023403/1 and the Newton Trust, and forms part of a collaboration between the University of Cambridge, Massachusetts Institute of Technology (MIT) and University of British Columbia (UBC).

\section{References}

[1] De Flander K. The role of bamboo in global modernity: from traditional to innovative construction material. Thesis: Wageningen University, Wageningen Netherlands; 2005.

[2] Yiping L et al. Technical Report 32: Bamboo and Climate Change Mitigation. Beijing, China: INBAR; 2010.

[3] Harries KA, Sharma B, Richard MJ. Structural use of full culm bamboo: the path to standardization. Int J Archit Eng Constr 2012;1(2):66-75.

[4] Gatóo A, Sharma B, Bock M, Mulligan H, Ramage M. Sustainable structures: bamboo standards and building codes. Proc ICE Eng Sustainability 2014;167(5):189-96.

[5] Chung KF, Yu WK. Mechanical properties of structural bamboo for bamboo Scaffoldings. Eng Struct 2002;24:429-42.

[6] Kaminsky S. Engineered bamboo houses for low-income communities. Struct Eng 2013;91(10):14-23. 
[7] Muthukaruppan R. Hong Kong - bastion of bamboo scaffolding. Proc ICE Civ Eng 2008;161(4):177-83.

[8] Trujillo DJA, Ramage M, Change W. Lightly modified bamboo for structural applications. Proc Inst Civ Eng Constr Mater 2013;166(4):238-47.

[9] Yu WK, Chung KF, Chan SL. Column buckling of structural bamboo. Eng Struct 2003;25:755-68.

[10] Yu WK, Chung KF, Chan SL. Axial buckling of bamboo columns in bamboo scaffolds. Eng Struct 2005;27:61-73.

[11] Bansal AK, Prasad TRN. Manufacturing laminates from sympodial bamboo - an Indian experience. J Bamboo Rattan 2004;3(1):13-22.

[12] Correal JF, Lopez LF. Mechanical properties of Colombian glued laminated bamboo. In: Mod Bamboo Struct. London, UK: CRC Press Taylor \& Francis Group; 2008. p. 121-8.

[13] Correal J, Ramirez F, Gonzalez S, Camacho J. Structural Behavior of Glued Laminated Guadua Bamboo as a Construction Material. In: Proceedings of the 11th World Conference on Timber Engineering. Italy: Trentino; 2010.

[14] Huang D, Zhou A, Bian Y. Experimental and analytical study on the nonlinear bending of parallel strand bamboo beams. Constr Build Mater 2013;44:592-5.

[15] Lee AWC, Bai X, Bangi AP. Selected properties of laboratory-made laminatedbamboo lumber. Holzforschung 1998;52:207-10.

[16] Mahdavi M, Clouston PL, Arwade SR. A low-technology approach toward fabrication of laminated bamboo lumber. Constr Build Mater 2012; 29(4):257-62.

[17] Pereira MA, Faria OB. Bambu Project: Mechanical Characteristics of the Glued Laminated Bamboo. Thailand: In Proceedings from the VIII World Bamboo Congress; 2009. pp. 135-150.

[18] Sinha A, Way D, Mlasko S. Structural performance of glued laminated bamboo beams. J Struct Eng 2014;140(1).

[19] Sulastiningsih IM, Nurwati. Physical and mechanical properties of laminated bamboo board. J Trop For Sci 2009;21(3):246-51.

[20] Xiao Y, Yang RZ, Shan B. Production, environmental impact and mechanical properties of glubam. Constr Build Mater 2013;44:765-73.

[21] Zhou A, Bian Y. Experimental study on the flexural performance of parallel strand bamboo beams. Sci World J 2014. http://dx.doi.org/10.1155/2014/ 181627.

[22] Sharma B, Gatoo A, Bock M, Mulligan H, Ramage M. Engineered bamboo: state of the art. Proc ICE Constr Mater 2014. http://dx.doi.org/10.1680/coma. 14.00020 .

[23] van der Lugt P. Design Interventions for Stimulating Bamboo Commercialization: Dutch Design meets Bamboo as a Replicable Model. Delft, Netherlands: VSSD; 2008.

[24] BS. British Standard 373-1957: methods of testing small clear specimens of timber. London, UK: British Standards Institution; 1957.
[25] ASTM. ASTM D143-09: standard test methods for small clear specimens of timber. West Conshohocken, PA, USA: ASTM International; 2009.

[26] BS. British standard EN 408-2010: timber structures - structural timber and glue-laminated timber. London, UK: British Standards Institution; 2010.

[27] Ghavami K and AB Marinho (2001). Determinição das propriedades mecanicas dos bambus das especies: moso, matake, Guadua angustifolia, guadua tagoara e Dendrocalamus giganteus, para utilização na engenharia. Rio de Janeiro: PUC-Rio, Publicação RMNC-1 Bambu 01/2001 (in Portuguese).

[28] de Vos V. Bamboo for exterior joinery: a research in material properties and market perspectives. Thesis: Larenstein University, Leeuwarden, Netherlands; 2010.

[29] Lavers GM (2002) The strength properties of timber, 3rd edition. Building Research Establishment (BRE) Report Series, London, UK.

[30] Kretschmann, DE (2010) Mechanical Properties of Wood. In Wood Handbook, General Technical Report FPL-GTR-190. U.S. Department of Agriculture, Forest Service, Forest Products Laboratory, Madison, WI, Chapter 5, pp. 5-1 - 5-46.

[31] Kretschmann DE, Moody RC, Pellerin RF, et al. (1993) Effect of various proportions of juvenile wood on laminated veneer lumber. Technical Report FPL-RP-521. U.S. Department of Agriculture, Forest Service, Forest Products Laboratory, Madison, WI.

[32] Clouston P, Lam F, Barret JD. Incorporating size effects in the Tasi-Wu strength theory for Douglas-fir laminated veneer. Wood Sci Technol 1998; 32(3):215-26.

[33] Li H, Zhang Q Huang D, Deeks AJ. Compressive performance of laminated bamboo. Compos B 2013;54:319-28.

[34] Amada S, Untao S. Fracture properties of bamboo. Compos B Eng 2001; 32(5):451-9.

[35] CES. Cambridge engineering selector edupack software. Cambridge, UK: Granta Design Limited; 2013.

[36] BS. British standard EN 384-2010: structural timber - determination of characteristic values of mechanical properties and density. London, UK: British Standards Institution; 2010.

[37] CSA. Chinese Standards Agency JG/T199: testing methods for physical and mechanical properties of bamboo used in building. Beijing, China: Chinese Standards Agency; 2007.

[38] Dinwoodie JM. Timber - a review of the structure - mechanical property relationship. J Microsc 1975;104(1):3-32.

[39] Wang H, Li W, Ren D. A two-variable model for predicting the effects of moisture content and density on compressive strength parallel to the grain for moso bamboo. J Wood Sci 2014. http://dx.doi.org/10.1007/s10086-014-1419-X.

[40] Xu Q, Harries KA, Li X, Lui Q, Gottron J. Mechanical properties of structural bamboo following immersion in water. Eng Struct 2014;81:230-9. 